OPEN ACCESS

Edited by:

Vassilios S. Nikolaou,

University of Athens, Greece

Reviewed by:

Alexandre Terrier,

EPFL, Switzerland

Claudia Di Bella,

St Vincent's Hospital, Australia

*Correspondence:

Michael David Hellman

michael_d_hellman@rush.edu

Specialty section: This article was submitted to

Orthopedic Surgery,

a section of the journal

Frontiers in Surgery

Received: 24 September 2015

Accepted: 09 November 2015

Published: 01 December 2015

Citation:

Levy DM, Hellman MD, Harris JD,

Haughom B, Frank RM and Nho SJ

(2015) Prevalence of Cam

Morphology in Females with

Femoroacetabular Impingement.

Front. Surg. 2:61.

doi: 10.3389/fsurg.2015.00061

\section{Prevalence of Cam Morphology in Females with Femoroacetabular Impingement}

\author{
David M. Levy ${ }^{1}$, Michael D. Hellman ${ }^{1 *}$, Joshua D. Harris ${ }^{2}$, Bryan Haughom ${ }^{1}$, \\ Rachel M. Frank ${ }^{1}$ and Shane J. Nho ${ }^{1}$
}

${ }^{1}$ Department of Orthopedic Surgery, Hip Preservation Center, Rush University Medical Center, Chicago, IL, USA, ${ }^{2}$ Houston Methodist Hip Preservation Center, Houston Methodist Orthopedics \& Sports Medicine, Houston Methodist Hospital, Houston, TX, USA

Cam and pincer are two common morphologies responsible for femoroacetabular impingement (FAl). Previous literature has reported that cam deformity is predominantly a male morphology, while being significantly less common in females. Cam morphology is commonly assessed with the alpha angle, measured on radiographs. The purpose of this study is to determine the prevalence of cam morphology utilizing the alpha angle in female subjects diagnosed with symptomatic FAl. All females presenting to the senior author's clinic diagnosed with symptomatic FAl between December 2006 and January 2013 were retrospectively reviewed. Alpha $(\alpha)$ angles were measured on anteroposterior and lateral (Dunn $90^{\circ}$, cross-table lateral, and/or frog-leg lateral) plain radiographs by two blinded physicians, and the largest measured angle was used. Using Gosvig et al.'s classification, alpha angle was characterized as (pathologic $\left.>57^{\circ}\right)$, borderline $\left(51-56^{\circ}\right)$, subtle $\left(46-50^{\circ}\right)$, very subtle $\left(43-45^{\circ}\right)$, or normal $\left(\leq 42^{\circ}\right)$. Three hundred and ninety-one patients (438 hips) were analyzed (age 36.2 \pm 12.3 years). Among the hips included, 35.6\% were normal, $14.6 \%$ pathologic, $15.1 \%$ borderline, $14.6 \%$ subtle, and $20.1 \%$ very subtle. There was no correlation between alpha angle and patient age $(R=0.17)$ or body mass index $(R=0.05)$. The intraclass correlation coefficient for $\alpha$-angle measurements was 0.84 . Sixty-four percent of females in this cohort had an alpha angle $>42^{\circ}$. Subtle cam deformity plays a significant role in the pathoanatomy of female patients with symptomatic FAl. As the majority of revision hip arthroscopies are performed due to incomplete cam correction, hip arthroscopists need to be cognizant of and potentially surgically address these subtle lesions.

\section{Keywords: femoroacetabular impingement, cam, female, alpha angle, head-neck offset}

\section{INTRODUCTION}

Femoroacetabular impingement (FAI) is a pathologic condition described by Ganz et al. (1) in which there is abnormal contact between the femoral head and acetabulum leading to hip pain, labral tears, chondral injuries, and early osteoarthritis (1-8). The two most common types of FAI are cam and pincer. Pincer-type FAI results from increased acetabular depth or overcoverage, while camtype FAI is a consequence of decreased femoral head-neck offset. The most common location of the cam deformity (asphericity) is at the anterolateral femoral head-neck junction, which increases 
shear at the chondrolabral junction of the anterosuperior acetabulum during deep flexion and rotational maneuvers. The magnitude of a cam deformity may be measured by a number of imaging parameters. Initially described by Notzli et al. (9) on axial oblique magnetic resonance imaging (MRI) parallel to the plane of the femoral neck, the alpha $(\alpha)$ angle describes where the head-neck junction loses sphericity. The alpha angle has been extrapolated to plain radiographs and computed tomography (CT). In a healthy population, the average $\alpha$ angle is estimated at $42^{\circ}(9)$; larger $\alpha$ angles may indicate the presence of a cam.

Cam and pincer morphologies are thought to predominate in men and women, respectively (10-14). The physiologic development of the hip joint differs between males and females, and there are different hypotheses to explain the association (15). Females have earlier closure of the pelvic and proximal femoral physes vs. males (16). In males, the formation and size progression of the cam morphology is around the time of rapid longitudinal growth (ages 12-16) and is associated with impact sports (e.g., hockey, football, basketball, and soccer) (17-19).

The prevalence and characterization of cam morphology is increasingly recognized in males. However, it is underrepresented and potentially unrecognized in females. The purpose of this study is to determine the prevalence of cam morphology in non-arthritic females with symptomatic intra-articular hip pain. The study hypothesis is that the prevalence of female cam impingement is higher than typically reported in the orthopedic literature.

\section{MATERIALS AND METHODS}

New female patients presenting to the senior author's office with a chief complaint of "hip pain" between December 2006 and January 2013 were considered. Inclusion criteria included age under 65 years, Tönnis arthritis grade (20) of 0 or 1 , adequate anteroposterior (AP) pelvis and lateral (Dunn $90^{\circ}$, cross-table lateral, and/or frog-leg lateral) hip radiographs, and a clinical history and exam consistent with intra-articular hip pathology. Adequacy of AP radiographs was determined by symmetry of obturator foramina, and distance of pubic symphysis and coccygeal tip (separated by $1.5-2 \mathrm{~cm}$ ). Subjective clinical evaluation consistent with intra-articular pathology demonstrated deep groin pain, worse with deep flexion and rotational maneuvers, worse with sitting rather than standing, pain with putting on socks and shoes, and worse with activity and better with rest. Objective physical examination demonstrated positive impingement testing and decreased hip flexion and internal rotation. Subjects with hip dysplasia (lateral center edge angle $<20^{\circ}$, anterior center edge angle $<20^{\circ}$, Tönnis angle $>10^{\circ}$, or femoral head extrusion index $>25 \%$ ) or prior hip surgery were excluded.

Radiographs were reviewed retrospectively. Tönnis grades were documented and $\alpha$ angles measured on all AP-pelvis and lateral radiographs as described by Notzli et al. (Figure 1) (9). The center of the femoral head, the central axis of the femoral neck, and the resultant $\alpha$ angle were determined using measurement tools available in the MedVIEW Picture Archive Communication System (PACS) software (Aspyra, West Lake Village, CA, USA). Lateral views included frog-leg lateral, cross-table lateral, and/or $90^{\circ}$-Dunn lateral positioning. The largest $\alpha$ angle was used. For each subject, demographic data, including age, ethnicity, and body mass index (BMI), was collected. In order to evaluate the prevalence of cam-type deformity, all patients were classified according to the criteria defined by Gosvig et al. (pathologic $>57^{\circ}$ and borderline $\left.51-56^{\circ}\right)(21)$. Additionally, patients were classified as having subtle $\left(46-50^{\circ}\right)$ or very subtle $\left(43-45^{\circ}\right)$ cam morphologies. Normal $\alpha$ angles were defined as $\leq 42^{\circ}(9)$.

Pearson's correlation was used between $\alpha$-angle measurements, age, and BMI. Student's $t$-test was performed to compare $\alpha$-angle and ethnicity and to compare measurements between different radiographic views. Measurements were performed by two senior resident physicians. An intraclass correlation coefficient (ICC) was found between the two sets of measurements. $p$-Values of $<0.05$ were considered significant. All statistical tests were performed using SPSS software for Windows, version 13.0 (SPSS, Chicago, IL, USA).

\section{RESULTS}

A total of 969 females were presented to the senior author's clinic between December 2006 and January 2013 with a chief complaint
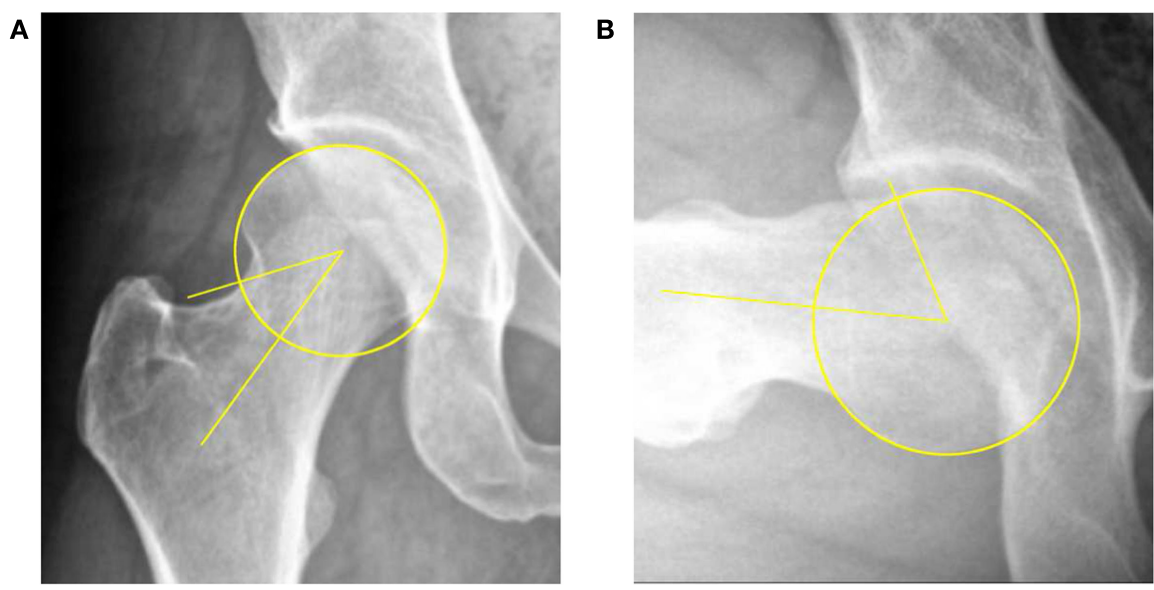

FIGURE 1 | Determination of head-neck offset by measurement of the $\alpha$ angle on AP (A) and $90^{\circ}$-Dunn lateral (B) radiographs. 
of "hip pain." Three hundred and ninety-one patients (438 hips) were eventually diagnosed with FAI and had adequate radiographs for inclusion. The mean age was $36.2 \pm 12.3$ years (range, $12-66$ ). The mean height was $65.3 \pm 8.7 \mathrm{in}$, weight $145.9 \pm 37.1 \mathrm{lbs}$, and BMI $24.0 \pm 5.0 \mathrm{~kg} / \mathrm{m}^{2}$. Ninety-eight percent were Caucasian. One hundred and ninety-three patients $(49.4 \%)$ had isolated impingement of the right hip, 151 (38.6\%) had isolated left hip impingement, and 47 (12.0\%) had bilateral impingement.

Table 1 lists the distribution of the mean largest $\alpha$ angle measured in the study population. The overall mean $\alpha$ angle was $48.2 \pm 11.9^{\circ}$. A deformity that was subtle or greater was present in $44.3 \%$ of hips, and $64.4 \%$ had a deformity very subtle or greater. There was no correlation $(R=0.17)$ between patients' age and size of the cam lesion nor was there a correlation $(R=0.05)$ between patients' BMI and size of the cam lesion. There was no difference between the ethnicity of the patient and size of the cam lesion $(p=0.10)$. Interobserver correlation coefficient for $\alpha$-angle measurements was 0.84 .

Table 2 lists the distribution of mean $\alpha$ angles measured on the respective views. The mean $\alpha$ angle measured on frog-leg lateral views was significantly greater than that measured on AP, crosstable lateral, and $90^{\circ}$-Dunn lateral views $(p<0.001, p=0.02$, and $p<0.001$, respectively). The mean angle measured on AP view was less than that of the cross-table lateral $(p=0.09)$ and significantly less than that of the $90^{\circ}$-Dunn lateral view $(p<0.001)$. There was no significant difference between the cross-table lateral and $90^{\circ}$-Dunn lateral views $(p=0.36)$.

\section{DISCUSSION}

Cam deformities have traditionally been associated with young male athletes, while pincer impingement has been described as a disease of middle-aged women (10-14). The current investigation's data suggest that there is a significantly higher prevalence of cam deformities found in symptomatic female patients. In this retrospective cohort of 391 women (438 hips) with symptomatic FAI, $29.7 \%$ had an $\alpha$ angle $>50.5^{\circ}$, compared to just $5.4 \%$ of asymptomatic females presented by Hack et al. (12).

TABLE 1 | Distribution of $\alpha$-angle.

\begin{tabular}{lc}
\hline Classification ( $\boldsymbol{\alpha}$-angle) & Number (\%) \\
\hline Pathologic $\left(>57^{\circ}\right)$ & $64(14.6)$ \\
Borderline $\left(51-56^{\circ}\right)$ & $66(15.1)$ \\
Subtle $\left(46-50^{\circ}\right)$ & $64(14.6)$ \\
Very subtle $\left(43-45^{\circ}\right)$ & $88(20.1)$ \\
Normal $\left(\leq 42^{\circ}\right)$ & $156(35.6)$ \\
\hline
\end{tabular}

TABLE 2 | Variation of $\alpha$-angle measurements by radiographic view.

\begin{tabular}{lcc}
\hline Radiographic view & $\begin{array}{c}\text { Mean } \boldsymbol{\alpha} \\
\text { angle }\left(^{(}\right)\end{array}$ & $\begin{array}{c}\text { Number of hips in which view } \\
\text { showed the largest } \boldsymbol{\alpha} \text { angle (\%) }\end{array}$ \\
\hline Anteroposterior (AP) & $41.3 \pm 11.0$ & $136(31.1)$ \\
Frog-leg lateral & $48.1 \pm 12.2$ & $114(26.0)$ \\
Cross-table lateral & $43.7 \pm 10.3$ & $14(3.2)$ \\
$90^{\circ}$-Dunn lateral & $44.2 \pm 8.6$ & $172(39.3)$ \\
\hline
\end{tabular}

${ }^{a}$ Two patients had identical $\alpha$ angle measurements on AP and frog-leg lateral views.
The notion that cam lesions occur predominantly in young males is supported by recent literature (12-14, 22). In 2010, Hack et al. evaluated hip MRI in 200 asymptomatic volunteers and 14\% of their subjects had cam deformities $>50.5^{\circ}, 79 \%$ of whom were male. They reported decreased head-neck offset in just $5.4 \%$ of the females enrolled (12). More recently in 2013, Leunig et al. assessed MRIs in 80 asymptomatic females and found 0 cam deformities $>57^{\circ}(13)$. While these studies suggest that cam deformities are rare in women, they are cross-sectional evaluations of asymptomatic patients and do not represent females who present with symptomatic impingement. Cam lesions can produce significant hip pain and motion restrictions $(23,24)$, and Miguel et al. have shown that symptomatic patients have significantly higher $\alpha$ angles compared to asymptomatic controls (25). Therefore, the prevalence of cam deformities in asymptomatic females may underestimate the prevalence of such deformities in those with symptoms.

In a recent assessment of FAI morphology in 100 men and women, Nepple et al. found an even greater percentage of cam deformities amongst females symptomatic enough to require surgery (26). Whereas the current cohort included some nonsurgical patients successfully treated with physical therapy, Nepple et al. reported that $88 \%$ of female patients requiring surgery had an $\alpha$ angle $>50^{\circ}$. Of note, they found that, while the majority of both men and women had cam impingement, the mean $\alpha$ angle was greater in men $\left(70.8^{\circ}\right.$ vs. $\left.57.6^{\circ}, p<0.001\right)$. Beaule et al. also reported smaller cam lesions in symptomatic females compared to males ( $n=30,73.3^{\circ}$ vs. $\left.58.7^{\circ}, p=0.009\right)(27)$.

The current study's findings indicate that symptomatic cam FAI may not be restricted to young males. Moreover, we feel that cam impingement should be thoroughly evaluated in all symptomatic females given the consequences of a missed cam deformity, including continued pain and the possibility of additional surgeries. The leading cause of revision FAI surgery is an inadequate cam resection $(28,29)$. It is, thus, important to scrutinize the head-neck region in an unbiased fashion and consider a femoral osteochondroplasty for both symptomatic men and women even though it is a technically demanding and time-consuming procedure. With adequate cam resection, both arthroscopic and open hip surgeries have shown excellent short- and midterm outcomes for relieving pain and improving function (30-40).

The $\alpha$-angle cut-off of $42^{\circ}$ for normal female morphology is based on the classification by Gosvig et al. and Notzli et al. (9, $21)$. This is a conservative threshold compared to the non-genderspecific threshold of $50.5^{\circ}$ used in other studies $(9,41-43)$. The clinical relevance of subtle $\left(46-50^{\circ}\right)$ and very subtle $\left(43-45^{\circ}\right)$ lesions has not yet been established. Abnormal $\alpha$-angle thresholds in females may need to be lowered compared to male patients to reflect gender-specific pathomechanisms, such as mixed impingement patterns, range of motion differences, and differences in hip girdle musculature $(44,45)$. Further studies are required to assess the extent of intra-articular pathology associated with these types of lesions and how they may correlate with the risk of developing osteoarthritis.

This study also highlights significant differences in the $\alpha$-angle measurements depending on the radiographic view. The frog-leg lateral view detected significantly larger cam deformities than each of the other three radiographic views. 
Clohisy et al. conducted a level II diagnostic study showing that the frog-leg lateral view provides accurate visualization of the femoral head-neck offset when distinguishing symptomatic FAI patients from asymptomatic controls (46). Barton et al. (47) validated both the $90^{\circ}$-Dunn and cross-table lateral views by comparing them to radial oblique reformatted MRI, which has been established as the gold-standard for detecting cam lesions $(9,48$, 49). A single AP view is less sensitive at finding cam deformities, which are typically anterosuperior between the 1:30 and 3:00 positions (47-49). The common consensus is that multiple views should be combined to assess multiple planes. In our study, cam lesions were most commonly detected on the most sensitive $90^{\circ}$ Dunn lateral view. The largest respective $\alpha$ angle was found on AP view in $31.1 \%$ of hips, but the head-neck offset from these hips was usually classified as normal. It should be noted that these comparisons represent pooled measurements and cannot speak to the accuracy of each radiograph per individual patient; some patients had all four views while others had only two.

To our knowledge, this study represents the largest cohort of symptomatic females evaluated for cam impingement. Radiographs were assessed using a validated system as demonstrated by our high interobserver correlation. Our findings are based on the largest $\alpha$ angles measured from all available radiographs, which minimizes the risk of having missed subtle deformities in different planes. If MRI were available for review, we would have had a greater sensitivity for detecting cam lesions and the prevalence of abnormal $\alpha$ angles may have been even higher than reported.

The limitations of this study are related to its retrospective and cross-sectional design. Therefore, no firm causal inferences can

\section{REFERENCES}

1. Ganz R, Parvizi J, Beck M, Leunig M, Nötzli H, Siebenrock KA. Femoroacetabular impingement: a cause for osteoarthritis of the hip. Clin Orthop (2003) 417:112-20. doi:10.1097/01.blo.0000096804.78689.c2

2. Agricola R, Heijboer MP, Bierma-Zeinstra SMA, Verhaar JAN, Weinans H, Waarsing JH. Cam impingement causes osteoarthritis of the hip: a nationwide prospective cohort study (CHECK). Ann Rheum Dis (2013) 72(6):918-23. doi: 10.1136/annrheumdis-2012-201643

3. Beck M, Leunig M, Parvizi J, Boutier V, Wyss D, Ganz R. Anterior femoroacetabular impingement: part II. Midterm results of surgical treatment. Clin Orthop (2004) 418:67-73. doi:10.1097/00003086-200401000-00012

4. Lavigne M, Parvizi J, Beck M, Siebenrock KA, Ganz R, Leunig M. Anterior femoroacetabular impingement: part I. Techniques of joint preserving surgery. Clin Orthop (2004) 418:61-6. doi:10.1097/00003086-200401000-00011

5. Bedi A, Dolan M, Hetsroni I, Magennis E, Lipman J, Buly R, et al. Surgical treatment of femoroacetabular impingement improves hip kinematics: a computer-assisted model. Am J Sports Med (2011) 39(Suppl 1):43S-9S. doi:10. $1177 / 0363546511414635$

6. Larson CM, Giveans MR, Taylor M. Does arthroscopic FAI correction improve function with radiographic arthritis? Clin Orthop (2011) 469(6):1667-76. doi: 10.1007/s11999-010-1741-6

7. Barros HJM, Camanho GL, Bernabé AC, Rodrigues MB, Leme LEG. Femoral head-neck junction deformity is related to osteoarthritis of the hip. Clin Orthop (2010) 468(7):1920-5. doi:10.1007/s11999-010-1328-2

8. Ng VY, Arora N, Best TM, Pan X, Ellis TJ. Efficacy of surgery for femoroacetabular impingement: a systematic review. Am J Sports Med (2010) 38(11):2337-45. doi:10.1177/0363546510365530

9. Nötzli HP, Wyss TF, Stoecklin CH, Schmid MR, Treiber K, Hodler J. The contour of the femoral head-neck junction as a predictor for the risk of anterior be made. Prospectively collected data from long-term follow-up of cohorts with both genders could clarify the clinical relevance of our findings and whether different degrees of cam deformities are associated with an increased risk of symptomatic hip arthritis. This study also lacks a formal evaluation for pincer lesions, so we cannot make an assessment of the prevalence and clinical relevance of mixed FAI presentations.

\section{CONCLUSION}

In conclusion, we have found that female patients with symptomatic FAI have a higher prevalence of cam lesions compared to prior reports of asymptomatic females. This may require lower gender-specific radiographic $\alpha$-angle thresholds to diagnose cam deformities in females. Future studies are required to assess this prospectively and help establish the clinical relevance of these findings.

\section{AUTHOR CONTRIBUTIONS}

DL: lead author on the study, contributed to all stages of study development. $\mathrm{MH}$ : second author, contributed to data analysis and manuscript drafting and editing. $\mathrm{JH}$ : third author, contributed to idea of study as well as preliminary data generation and editing of the manuscript. $\mathrm{BH}$ : fourth author, contributed to data acquisition ad drafting of manuscript. RF: fifth author, contributed to data analysis and editing of manuscript. SN: sixth author, contributed to study generation and drafting and editing of manuscript.

impingement. J Bone Joint Surg Br (2002) 84(4):556-60. doi:10.1302/0301620X.84B4.12014

10. Beck M, Kalhor M, Leunig M, Ganz R. Hip morphology influences the pattern of damage to the acetabular cartilage: femoroacetabular impingement as a cause of early osteoarthritis of the hip. J Bone Joint Surg Br (2005) 87(7):1012-8. doi:10.1302/0301-620X.87B7.15203

11. Clohisy JC, Knaus ER, Hunt DM, Lesher JM, Harris-Hayes M, Prather H. Clinical presentation of patients with symptomatic anterior hip impingement. Clin Orthop (2009) 467(3):638-44. doi:10.1007/s11999-008-0680-y

12. Hack K, Di Primio G, Rakhra K, Beaulé PE. Prevalence of cam-type femoroacetabular impingement morphology in asymptomatic volunteers. J Bone Joint Surg Am (2010) 92(14):2436-44. doi:10.2106/JBJS.J.01280

13. Leunig $M$, Jüni $P$, Werlen $S$, Limacher A, Nüesch E, Pfirrmann CW, et al. Prevalence of cam and pincer-type deformities on hip MRI in an asymptomatic young Swiss female population: a cross-sectional study. Osteoarthritis Cartilage (2013) 21(4):544-50. doi:10.1016/j.joca.2013.01.003

14. Gosvig KK, Jacobsen S, Sonne-Holm S, Gebuhr P. The prevalence of camtype deformity of the hip joint: a survey of 4151 subjects of the Copenhagen Osteoarthritis Study. Acta Radiol (2008) 49(4):436-41. doi:10.1080/ 02841850801935567

15. Pollard TCB, Khan T, Price AJ, Gill HS, Glyn-Jones S, Rees JL. Simulated hip arthroscopy skills: learning curves with the lateral and supine patient positions: a randomized trial. J Bone Joint Surg Am (2012) 94(10):e68. doi:10.2106/JBJS.K. 00690

16. Shultz SJ, Nguyen A-D, Schmitz RJ. Differences in lower extremity anatomical and postural characteristics in males and females between maturation groups. J Orthop Sports Phys Ther (2008) 38(3):137-49. doi:10.2519/jospt.2008.2645

17. Gerhardt MB, Romero AA, Silvers HJ, Harris DJ, Watanabe D, Mandelbaum BR. The prevalence of radiographic hip abnormalities in elite soccer players. Am J Sports Med (2012) 40(3):584-8. doi:10.1177/0363546511432711 
18. Siebenrock KA, Ferner F, Noble PC, Santore RF, Werlen S, Mamisch TC. The cam-type deformity of the proximal femur arises in childhood in response to vigorous sporting activity. Clin Orthop (2011) 469(11):3229-40. doi:10.1007/ s11999-011-1945-4

19. Silvis ML, Mosher TJ, Smetana BS, Chinchilli VM, Flemming DJ, Walker EA, et al. High prevalence of pelvic and hip magnetic resonance imaging findings in asymptomatic collegiate and professional hockey players. Am J Sports Med (2011) 39(4):715-21. doi:10.1177/0363546510388931

20. Tönnis D, Heinecke A. Acetabular and femoral anteversion: relationship with osteoarthritis of the hip. J Bone Joint Surg Am (1999) 81(12):1747-70.

21. Gosvig KK, Jacobsen S, Palm H, Sonne-Holm S, Magnusson E. A new radiological index for assessing asphericity of the femoral head in cam impingement. J Bone Joint Surg Br (2007) 89(10):1309-16. doi:10.1302/0301-620X.89B10. 19405

22. Gosvig KK, Jacobsen S, Sonne-Holm S, Palm H, Troelsen A. Prevalence of malformations of the hip joint and their relationship to sex, groin pain, and risk of osteoarthritis: a population-based survey. J Bone Joint Surg Am (2010) 92(5):1162-9. doi:10.2106/JBJS.H.01674

23. Ito K, Minka MA, Leunig M, Werlen S, Ganz R. Femoroacetabular impingement and the cam-effect. A MRI-based quantitative anatomical study of the femoral head-neck offset. J Bone Joint Surg Br (2001) 83(2):171-6. doi:10.1302/0301620X.83B2.11092

24. Murphy S, Tannast M, Kim Y-J, Buly R, Millis MB. Debridement of the adult hip for femoroacetabular impingement: indications and preliminary clinical results. Clin Orthop (2004) 429:178-81. doi:10.1097/01.blo.0000150307.75238.b9

25. Miguel OF, Cabrita HB, Rodrigues MB, Croci AT. A comparative radiographic investigation of femoroacetabular impingement in young patients with and without hip pain. Clinics (2012) 67(5):463-7. doi:10.6061/clinics/ 2012(05) 10

26. Nepple JJ, Riggs CN, Ross JR, Clohisy JC. Clinical presentation and disease characteristics of femoroacetabular impingement are sex-dependent. J Bone Joint Surg Am (2014) 96(20):1683-9. doi:10.2106/JBJS.M.01320

27. Beaulé PE, Zaragoza E, Motamedi K, Copelan N, Dorey FJ. Three-dimensional computed tomography of the hip in the assessment of femoroacetabular impingement. J Orthop Res (2005) 23(6):1286-92. doi:10.1016/j.orthres.2005. 03.011

28. Heyworth BE, Shindle MK, Voos JE, Rudzki JR, Kelly BT. Radiologic and intraoperative findings in revision hip arthroscopy. Arthroscopy (2007) 23(12):1295-302. doi:10.1016/j.arthro.2007.09.015

29. Philippon MJ, Schenker ML, Briggs KK, Kuppersmith DA, Maxwell RB, Stubbs AJ. Revision hip arthroscopy. Am J Sports Med (2007) 35(11):1918-21. doi:10. $1177 / 0363546507305097$

30. Alradwan H, Philippon MJ, Farrokhyar F, Chu R, Whelan D, Bhandari M, et al. Return to preinjury activity levels after surgical management of femoroacetabular impingement in athletes. Arthroscopy (2012) 28(10):1567-76. doi:10.1016/ j.arthro.2012.03.016

31. Botser IB, Jackson TJ, Smith TW, Leonard JP, Stake CE, Domb BG. Open surgical dislocation versus arthroscopic treatment of femoroacetabular impingement. Am J Orthop (2014) 43(5):209-14.

32. Matsuda DK, Carlisle JC, Arthurs SC, Wierks CH, Philippon MJ. Comparative systematic review of the open dislocation, mini-open, and arthroscopic surgeries for femoroacetabular impingement. Arthroscopy (2011) 27(2):252-69. doi:10.1016/j.arthro.2010.09.011

33. Ilizaliturri VM, Orozco-Rodriguez L, Acosta-Rodríguez E, Camacho-Galindo J. Arthroscopic treatment of cam-type femoroacetabular impingement: preliminary report at 2 years minimum follow-up. J Arthroplasty (2008) 23(2):226-34. doi:10.1016/j.arth.2007.03.016

34. Tran P, Pritchard M, O'Donnell J. Outcome of arthroscopic treatment for cam type femoroacetabular impingement in adolescents. ANZ J Surg (2013) 83(5):382-6. doi:10.1111/j.1445-2197.2012.06197.x
35. Bedi A, Zaltz I, De La Torre K, Kelly BT. Radiographic comparison of surgical hip dislocation and hip arthroscopy for treatment of cam deformity in femoroacetabular impingement. Am J Sports Med (2011) 39(Suppl):20S-8S. doi:10.1177/0363546511412734

36. Clohisy JC, St John LC, Schutz AL. Surgical treatment of femoroacetabular impingement: a systematic review of the literature. Clin Orthop (2010) 468(2):555-64. doi:10.1007/s11999-009-1138-6

37. Harris JD, Erickson BJ, Bush-Joseph CA, Nho SJ. Treatment of femoroacetabular impingement: a systematic review. Curr Rev Musculoskelet Med (2013) 6(3):207-18. doi:10.1007/s12178-013-9172-0

38. Byrd JWT, Jones KS. Prospective analysis of hip arthroscopy with 10-year followup. Clin Orthop (2010) 468(3):741-6. doi:10.1007/s11999-009-0841-7

39. Kemp JL, Collins NJ, Makdissi M, Schache AG, Machotka Z, Crossley K. Hip arthroscopy for intra-articular pathology: a systematic review of outcomes with and without femoral osteoplasty. Br J Sports Med (2012) 46(9):632-43. doi:10. 1136/bjsports-2011-090428

40. Nwachukwu BU, Rebolledo BJ, McCormick F, Rosas S, Harris JD, Kelly BT. Arthroscopic versus open treatment of femoroacetabular impingement a systematic review of medium- to long-term outcomes. Am J Sports Med (2015). doi:10.1177/0363546515587719

41. Kassarjian A, Cerezal L, Llopis E. Femoroacetabular impingement. Top Magn Reson Imaging (2006) 17(5):337-45. doi:10.1097/rmr.0b013e3180421 caf

42. Meyer DC, Beck M, Ellis T, Ganz R, Leunig M. Comparison of six radiographic projections to assess femoral head/neck asphericity. Clin Orthop (2006) 445:181-5. doi:10.1097/01.blo.0000201168.72388.24

43. Tannast M, Siebenrock KA, Anderson SE. . Femoroacetabular impingement: radiographic diagnosis - what the radiologist should know. Am J Roentgenol (2007) 188(6):1540-52. doi:10.2214/AJR.06.0921

44. Rylander J, Shu B, Favre J, Safran M, Andriacchi T. Functional testing provides unique insights into the pathomechanics of femoroacetabular impingement and an objective basis for evaluating treatment outcome. J Orthop Res (2013) 31(9):1461-8. doi:10.1002/jor.22375

45. Kolo FC, Charbonnier C, Pfirrmann CWA, Duc SR, Lubbeke A, Duthon VB, et al. Extreme hip motion in professional ballet dancers: dynamic and morphological evaluation based on magnetic resonance imaging. Skeletal Radiol (2013) 42(5):689-98. doi:10.1007/s00256-012-1544-9

46. Clohisy JC, Nunley RM, Otto RJ, Schoenecker PL. The frog-leg lateral radiograph accurately visualized hip cam impingement abnormalities. Clin Orthop (2007) 462:115-21. doi:10.1097/BLO.0b013e3180f60b53

47. Barton C, Salineros MJ, Rakhra KS, Beaulé PE. Validity of the alpha angle measurement on plain radiographs in the evaluation of cam-type femoroacetabular impingement. Clin Orthop (2011) 469(2):464-9. doi:10.1007/s11999-0101624-x

48. Rakhra KS, Sheikh AM, Allen D, Beaulé PE. Comparison of MRI alpha angle measurement planes in femoroacetabular impingement. Clin Orthop (2009) 467(3):660-5. doi:10.1007/s11999-008-0627-3

49. Dudda M, Albers C, Mamisch TC, Werlen S, Beck M. Do normal radiographs exclude asphericity of the femoral head-neck junction? Clin Orthop (2009) 467(3):651-9. doi:10.1007/s11999-008-0617-5

Conflict of Interest Statement: The authors did not receive any outside funding or grants in support of their research for or preparation of this work. Neither they nor a member of their immediate families received payments or other benefits or a commitment or agreement to provide such benefits from a commercial entity.

Copyright (c) 2015 Levy, Hellman, Harris, Haughom, Frank and Nho. This is an openaccess article distributed under the terms of the Creative Commons Attribution License (CC BY). The use, distribution or reproduction in other forums is permitted, provided the original author(s) or licensor are credited and that the original publication in this journal is cited, in accordance with accepted academic practice. No use, distribution or reproduction is permitted which does not comply with these terms. 